\title{
SEQÜÊNCIAS DEPOSICIONAIS DA FORMAÇÃO TACIBA (GRUPO ITARARÉ, NEOCARBONÍFERO A EOPERMIANO) NA REGIÃO DE MAFRA (SC), BACIA DO PARANÁ
}

\author{
LUIZ CARLOS WEINSCHÜTZ ${ }^{1} \&$ JOEL CARNEIRO DE CASTRO ${ }^{2}$
}

\begin{abstract}
Resumo A Formação Taciba constitui o terceiro grande ciclo de granodecrescência ascendente do Grupo Itararé, e é formada pelo membros Rio Segredo (arenito), Chapéu do Sol (diamictito) e Rio do Sul (ritmito, siltito e folhelho). Na região de Mafra, margem leste da Bacia do Paraná, não ocorre o arenito do Membro Rio Segredo, e o diamictito Chapéu do Sol, 65m de espessura, recobre bruscamente o Folhelho Lontras (que constitui o topo da Formação Campo Mourão, sotoposta). O estudo de quatro poços testemunhados, complementado com perfis de afloramentos vizinhos, possibilita identificar duas seqüências deposicionais para a Formação Taciba. No poço VR-1 a seqüência inferior Taciba-I, TC-I, é representada por um intervalo bastante espesso de diamictito, contendo intercalações de arenito argiloso maciço (slurry), siltito e ritmito fino, com feições de escorregamento, deformação plástica e diques arenosos, e localmente de um grande bloco de turbidito in situ, com clasto caído. Na parte superior do perfil o diamictito apresenta estratificação, bem como grandes e numerosos clastos caídos; lateralmente a oeste, no poço PP10, ocorrem duas sucessões faciológicas granocrescentes, com folhelho várvico, siltito e ritmito fino, contendo pseudonódulos de arenito, escorregamento e raros clastos caídos. Na seqüência TC-I, o trato de mar baixo seria representado pelo arenito do Membro Rio Segredo (ausente na área), e os sistemas acima descritos formariam os tratos de sistemas transgressivo e de mar alto. Um intervalo arenoso, com fácies e espessuras variáveis, representa o trato de mar baixo da seqüência Taciba-II, TC-II. No poço RB-3 são $52 \mathrm{~m}$ de turbiditos de leque canalizado (Arenito A3), sobreposto erosivamente a ritmitos várvicos e turbiditos delgados de uma bacia glaciolacustre, e sotoposto a diamictito glacial; este, por sua vez, é sucedido por uma delgada sucessão de conglomerado, arenito fossilifero bioturbado e siltito-folhelho, representando um trato transgressivo de sistemas deposicionais. No perfil S. Lourenço ocorre seção de 40m de arenito com estratificação sigmóide (Arenito A2), de origem flúvio-deltaica. No poço PP-10 a seqüência TC-II tem 4,5m de arenito de origem flúvio-estuarina (Arenito A4) com clastos caídos, enquanto no perfil Vila Ruthes desenvolve-se um sistema de deglaciação lateralmente equivalente, com varvito tipo "telha" sobreposto por arenito muito fino de frente deltaica (Arenito A1). Sobreposto ao Arenito A4, ocorrem no poço PP-10 dois ciclos granocrescentes formados por folhelho várvico, siltito e ritmito fino, em parte com clasto caído e escorregamento, de origem gláciomarinha plataformal e que constitui o trato de sistemas de mar alto, encerrando a sedimentação Taciba na área.
\end{abstract}

Palavras-chave: estratigrafia de sequencias; sedimentação glacial e interglacial; ciclo de deglaciação; turbidito canalizado; arenito flúvio-estuarino.

\begin{abstract}
DEPOSITIONAL SEQUENCES OF TACIBA FORMATION (ITARARÉ GROUP, LATE CARBONIFEROUS TO EARLY PERMIAN) IN MAFRA REGION, EASTERN PARANÁ BASIN The Taciba Formation constitutes the third major finingupward cycle of Itararé Group, and encompasses three members: Rio Segredo sandstone, Chapéu do Sol diamictite, and Rio do Sul rhythmite, siltstone and shale). In Mafra area, eastern margin of Paraná Basin, the Rio Segredo sandstone do not occur, and the Chapéu do Sol diamictite abruptly overlies the Lontras Shale (top unit of the underlying Campo Mourão Formation). The study of four cored wells and complementary nearby outcrops, allowed to identify two depositional sequences for Taciba Formation. In the Vila Ruthes well (VR-1) and outcrop section, the lower, Taciba-I sequence (TC-I) consists of a 65m-thick interval of diamictite with intercalations of massive argillaceous sandstone (slurry), siltitstone and thin rhythmite; these lithologies display slumping, contorted beds, sandstone dykes, and also a large, in situ turbidite block with dropstone. In its upper part the diamictite is stratified and contains abundant dropstones; it passes laterally in well PP-10 (westwards) to a coarsening-upwards succession of varvic shale, siltstone and slumped thin rhythmite. In the absence of a lowstand tract (Rio Segredo Member), all the above lithofacies can be assigned to transgressive and highstand systems tract. A sandstone interval displaying different facies and thicknesses occur at the base of sequence TC-II, possibly as a lowstand systems tract. In RB-3 well there are 52m of channelized turbidites (A3 Sandstone) overlying thin-bedded rhythmites with dropstones of a glaciolacustrine or marine setting; in the outcrop section which complements the SL-2 well, it occurs 40m of sigmoidal sandstones of fluvio-deltaic origin (A2 Sandstone). The PP-10 well recovered $4.5 \mathrm{~m}$ of fluvial-estuarine sandstone (A4 Sandstone), and in Vila Ruthes outcrop section (complementary of well VR-1) the A1 Sandstone is composed of a deglaciation system with dropstone-bearing varvites overlain by delta front sandstone. The outcrop section which complements RB-3 well is composed of a deglaciation interval with 10m-thick stratified diamictite, overlain by thin stratified conglomerate and sandstone, bioturbated fossiliferous sandstone and shale, representing the transgressive systems tract. Finally the PP-10 well sampled the upper part of sequence TC-II: two coarsening-upward successions of varved shale, siltstone and rhythmite, with slump structures and few dropstones, forming the highstand systems tract of the sequence.
\end{abstract}

Key-words: sequence stratigraphy; glacial and interglacial sedimentation; deglaciation cycle; channelized turbidite; estuarine sandstone.

INTRODUÇÃO A Formação Taciba, na concepção de França \& Potter (1988), constitui o terceiro grande ciclo de afinamento ascendente do Grupo Itararé (Néocarbonífero a Éopermiano),
Bacia do Paraná, e engloba os membros Rio Segredo (arenito), Chapéu do Sol (diamictito) e Rio do Sul (ritmito, siltito e folhelho). Aquela unidade corresponde à Formação Rio do Sul de

\footnotetext{
1 - Programa de Pós-Graduação em Geociências-Área de Geologia Regional - Universidade Estadual Paulista luizcwei@ibest.com.br

2 - Programa de Pós-Graduação em Geociências-Área de Geologia Regional - Universidade Estadual Paulista jocastro@rc.unesp.br 


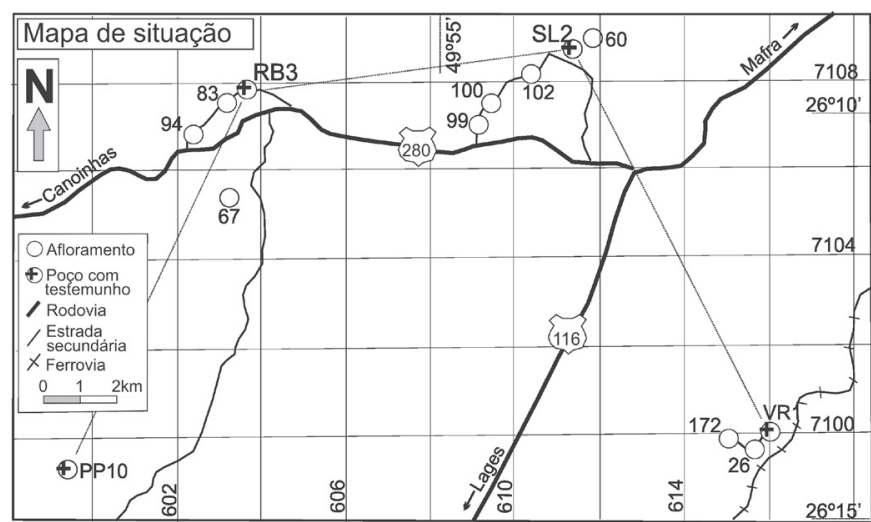

Figura 1. Mapa de localização dos quatro poços e afloramentos vizinhos, a sudoeste de Mafra.

Schneider et al. (1974), desde que se exclua da porção inferior desta o "Folhelho Lontras" (posicionado por França \& Potter no topo de sua Formação Campo Mourão). Por outro lado, o terceiro ciclo/Formação Taciba compreende a quarta e quinta seqüências do Grupo Itararé na região de Mafra (este trabalho), correspondendo aos intervalos médio e superior da Formação Rio do Sul na definição de Weinschütz (2001).

Como se verá a seguir, a Formação Taciba, do mesmo modo que a Formação Campo Mourão (segundo grande ciclo do Grupo Itararé; Weinchütz \& Castro, no prelo), comporta duas seqüências deposicionais, TC-I e TC-II, que tem origens glacial e interglacial, respectivamente. Contribuem para o arcabouço cronoestratigráfico da Formação Taciba os dados de quatro poços, três dos quais doados pela Fundação Geosol, complementados por afloramentos e perfis de superfície. Destaca-se na metade inferior da seqüência TC-I o espesso corpo mapeável de diamictito maciço Chapéu do Sol, de origem gláciomarinha, que se apóia diretamente no Folhelho Lontras, já que o Arenito Rio Segredo está ausente na área de Mafra. Na parte inferior da seqüência TC-II, o destaque é um expressivo corpo arenoso com diferentes espessuras e origens (arenitos A1 a A4), seguido por uma sucessão de deglaciação e por espesso folhelho marinho plataformal; sugere-se que esses três sistemas representem respectivamente os tratos de mar baixo, transgressivo e mar alto de TC-II.

BASE DE DADOS E MÉTODOS A localização de quatro poços, e de afloramentos complementares aos mesmos, é apresentada na figura 1. Três dos poços foram doados pela Fundação Geosol, e receberam as siglas VR-1 (Vila Ruthes), SL-2 (São Lourenço) e RB-3 (Rio Butiá); cada poço alcançou $60 \mathrm{~m}$, em média (os números indicam simplesmente a ordem de perfuração dos poços). O quarto poço, do acervo da CPRM/DNPM, é o PP-10 (Projeto Pioneiro), e dispõe de perfis raio-gama e elétrico para calibração dos testemunhos. A aplicação do método da Estratigrafia de Seqüências a depósitos formados em condições climáticas glaciais, em bacia do tipo Intracratônica, constitui um grande desafio. Por exemplo, como enquadrar espessas seções de diamictitos gláciomarinhos, como o da parte inferior da seqüência TC-I? Devido às grandes variações laterais das fácies e ciclos de fácies, principalmente na margem da bacia, é difícil a correlação entre poços distantes mais de $20 \mathrm{~km}$ entre si, conforme observado na margem leste paranaense por Castro (1999). Não é o caso atual, onde a distância entre os quatro poços, de $12 \mathrm{~km}$ em média, possibilita uma razoável compreensão do arcabouço cronoestratigráfico de seqüências (figura 1). Assim, busca-se identificar ciclos de fácies ( $\sim$ parasseqüência), conjunto de ciclos de fácies ( $\sim$ conjunto de parasseqüências), e os tratos de sistemas que constituem a seqüência deposicional.

De qualquer forma, os resultados tem sido bastante promissores, reforçando e detalhando a proposta de três ciclos/formações para o Grupo Itararé (França \& Potter, 1988), cada qual tornando-se mais marinho no sentido ascendente, e onde podem caber pelo menos seis seqüências deposicionais (duas em cada ciclo/Formação).

\section{OS POÇOS TESTEMUNHADOS}

Poço SL-2 O poço SL-2 testemunhou 30m de Folhelho Lontras (unidade superior da Formação Campo Mourão), recoberto por 30m de diamictito da Formação Taciba; nota-se na base desta última a ausência do Arenito Rio Segredo na área de Mafra (Figura 2). Tal diamictito alcança espessura de $65 \mathrm{~m}$, aí incluídos os $35 \mathrm{~m}$ da grande pedreira em cujo piso foi executada a sondagem. O contato do referido corpo de diamictito com o Folhelho Lontras é abrupto; nota-se em sua parte basal , entretanto, uma textura síltica semelhante a dos siltitos arenosos (turbiditos) intercalados na parte superior do Lontras, exceto pela presença de raros e pequenos clastos caídos (dropstones) no "diamictito" (Figura 2; ver prancha 3-E de Weinschütz \& Castro, 2005).

Assim, a fácies Diamictito Dm é maciça e bastante homogênea, apresentando clastos caídos que alcançam $3,5 \mathrm{~cm}$; sua origem deve-se a fluxos de suspensão, com a contribuição dos clastos caídos de geleiras flutuantes (rain-out diamictite). $\mathrm{Na}$ pedreira adjacente, onde foi iniciado o poço, notam-se algumas intercalações síltico-arenosas bastante deformadas, sugerindo a atuação de fluxos gravitacionais pastosos (slurries).

Poço VR-1 Nos quase sessenta metros testemunhados do poço Vila Ruthes, VR-1, pode-se identificar quatro associações faciológicas que são, em ordem ascendente (Figura 2):

(59,2 a 36,2m), Diamictito inferior - Dm;

(36,2 a 24,0m), Diamictito com intercalações arenosas - DA;

(24,0 a 15,1m), Arenito, Siltito, Ritmito delgado com liquefação e escorregamento -ASR;

$(15,1 \mathrm{~m}$ a zero), Diamictito superior - Dm.

Os diamictitos inferior e superior, fácies Dm, são maciços, com matriz lamítica, e têm lâminas e lentes arenosas inclinadas de arenito argiloso (escorregamento?); os clastos caídos alcançam $8 \mathrm{~cm}$ (Figuras 2, 3-E).

A fácies DA exibe uma textura síltica, clastos caídos e lentes arenosas inclinadas $(0,1$ a $0,25 \mathrm{~m}$ de espessura), que se tornam mais freqüentes para o topo do intervalo (Figuras 2, 3-A).

A associação ASR é formada por Arenito, Siltito e Ritmito delgado. $\mathrm{O}$ arenito mostra estratos com espessura entre 0,5 e 2,0m, é maciço e argiloso, e tem pseudonódulos arenosos e intraclastos argilosos (slurry; Figuras 2, 3-C e 3-D). Aquela litologia intercala-se com siltito, tendo um aspecto rítmico ou maciço/caótico e feições de escorregamento (Figuras 2, 3-E). Os ritmitos delgados de siltito e folhelho apresentam diques de arenito (Figuras 3-B, 3-D).

As três associações iniciais Dm-DA-ASR provavelmente constituem um ciclo tornando-se mais arenoso e "limpo" para cima (sandier, cleaning-up), com mais de $44 \mathrm{~m}$ de espessura (Figura 2).

O diamictito superior passa acima, na pedreira adjacente ao poço, a ritmitos areno-argilosos delgados e ritmitos espessos com deformação plástica e feições de escorregamento; lateralmente ocorre um bloco intacto de turbidito, com $1 \mathrm{~m}$ de espessura por $2 \mathrm{~m}$ de largura, contendo clasto caído (Weinschütz, 2001). Isto sugere que parte de um corpo turbiditico mais extenso rompeu e deformou-se plasticamente, resultando no depósito atual que lembra a fácies ASR do poço VR-1 (ver na Figura 7 


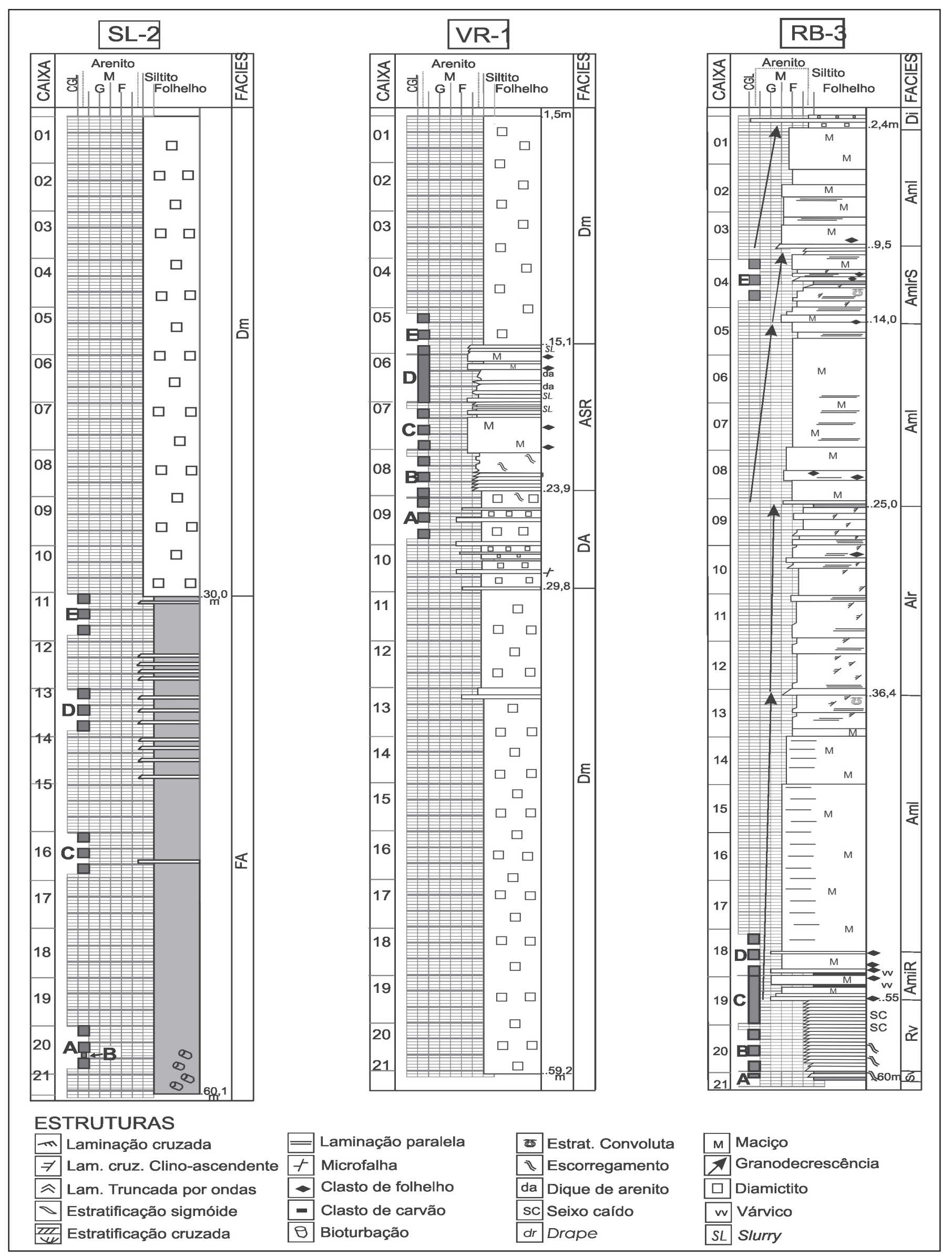

Figura 2. Perfis sedimentológicos dos poços SL-2, VR-1 e RB-3. As letras A a E indicadas à esquerda dos perfis dos poços VR-1 e RB-3 posicionam as fotografias dos testemunhos das Figuras 3 e 4; as indicadas no perfil do poço SL-2 referem-se ao Folhelho Lontras e estão sendo apresentadas em Weinschütz \& Castro (2005). 


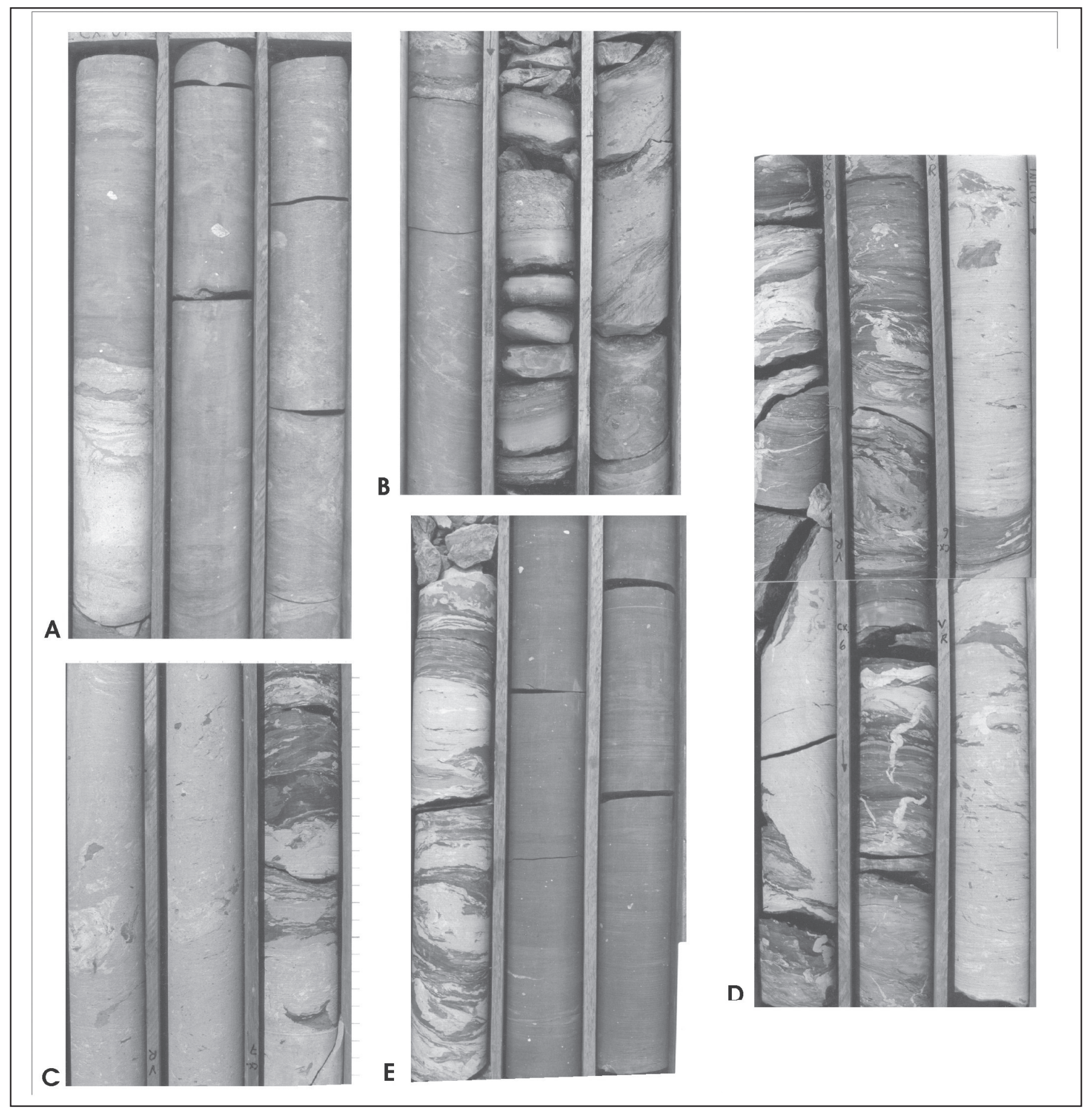

Figura 3. Associações faciológicas interpretadas no poço VR-1. A. Associação DA. Diamictito maciço, com intercalação de arenito maciço na base. B. Associações DA e ASR. Diamictito com matriz síltica, seixos caídos de até 2cm e escorregamento (DA), sobreposto por ritmito siltito-folhelho (centro) e siltito arenoso com escorregamento e clasto caído (ASR). C. Associação ASR. Arenito maciço, argiloso, com intraclastos de folhelho e liquefação (slurry), recoberto por siltito com lentes arenosas (ritmito?) e escorregamento. D. Associação ASR. Siltito-folhelho (ritmito?) com escorregamentos e diques de arenito, ao centro, e estratos de arenito maciço, argiloso, com intraclastos pelíticos (slurry). E. Associações ASR e Dm. Intercalações de siltito e arenito com escorregamento, recoberto por diamictito. Diâmetro dos testemunhos é de 7,5cm. Caixas 9 a 5, Figura 2. Base da caixa no canto inferior esquerdo, e topo no superior direito.

o perfil integrado do poço e afloramentos de Vila Ruthes). Este novo ciclo mais arenoso-"limpo" para cima, com as fácies Dm e ASe, tem $20 \mathrm{~m}$ de espessura. Assim, tais ciclos poderiam indicar uma progressão temporal de processos geológicos, desde escorregamentos (fluxos plásticos), slurries (fluxos pastosos) e finalmente turbiditos (fluxos de turbidez), em um contexto de águas relativamente profundas.
Poço RB-3 Os sessenta metros testemunhados do poço Rio Butiá, RB-3, são representados essencialmente por $52,5 \mathrm{~m}$ de um corpo arenoso, encaixado entre $5,0 \mathrm{~m}$ de siltito laminado e ritmito várvico na base do poço, e $2,5 \mathrm{~m}$ de diamictito para o topo (Figura 2).

Na porção inferior do poço (60 a $55 \mathrm{~m})$, ocorre a fácies $\mathbf{S v}$, siltito laminado, várvico, com dobras de escorregamento ou as- 


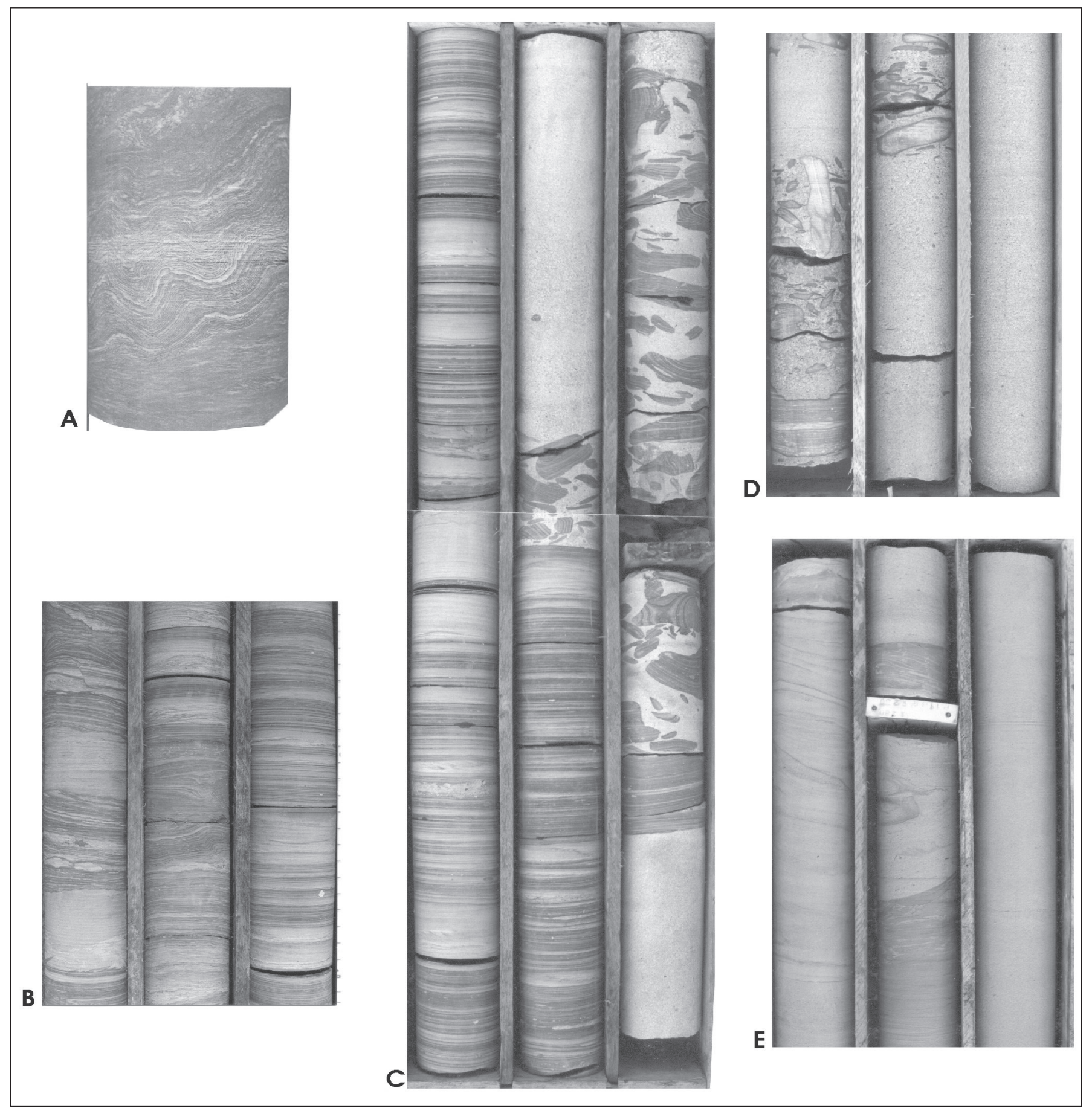

Figura 4. Associações faciológicas interpretadas no poço RB-3. A. Associação Sv. Siltito maciço "liquefeito" na base e topo da amostra, e ritmito milimétrico (varvito) com dobras de escorregamento. B. Associação Rv. Ritmito arenito-folhelho em pares milimétricos (varvito), com níveis centimétricos de arenito gradando a folhelho (turbidito Tce). Notar falha sinsedimentar (canto esquerdo superior) e clasto caído (canto direito inferior). C. Associações Rv e AmiR. Ritmito várvico recoberto abruptamente (meio da caixa) por arenito grosso, intraclástico, gradando a arenito médio a fino, maciço; notar níveis de ritmito várvico sobreposto ao arenito maciço, e arenito grosso cortando conglomerado (topo). Pequenos ciclos de afinamento do arenito intraclástico para arenito maciço. D. Associações AmiR e Aml. Na base, ritmito várvico dentro do arenito; sucedem pequenos ciclos de arenito maciço e conglomerado intraclástico. Na raia da direita, arenito maciço (associação Aml). E. Associação AmlrS. Estratos de arenito fino e muito fino, maciço a laminação cruzada clino-ascendente, gradando a Siltito, ambos com intensa liquefação. Diâmetro dos testemunhos, 7,5cm; caixas 21 a 18, Figura 2. Base no canto inferior esquerdo, topo no superior direito.

pecto maciço devido a liquefação (Figuras 2, 4-A), sobreposta por ritmito várvico, fácies $\mathbf{R v}$. Esta fácies é caracterizada por pares areno-argilosos milimétricos ou com espessuras entre 1 e $8 \mathrm{~cm}$; neste caso, a espessura maior é devida à presença de arenitos com laminação cruzada clino-ascendente (turbidito delgado), enquanto o componente argiloso mantém a espessura milimétrica. A fácies Rv também mostra dobras de escorregamento, microfalhas e raros clastos caídos de até $1 \mathrm{~cm}$ (Figuras 4-B, 4-C). Tais ritmitos, em escala milimétrica ou centimétrica, são interpretados como varvitos (varves sazonais). 


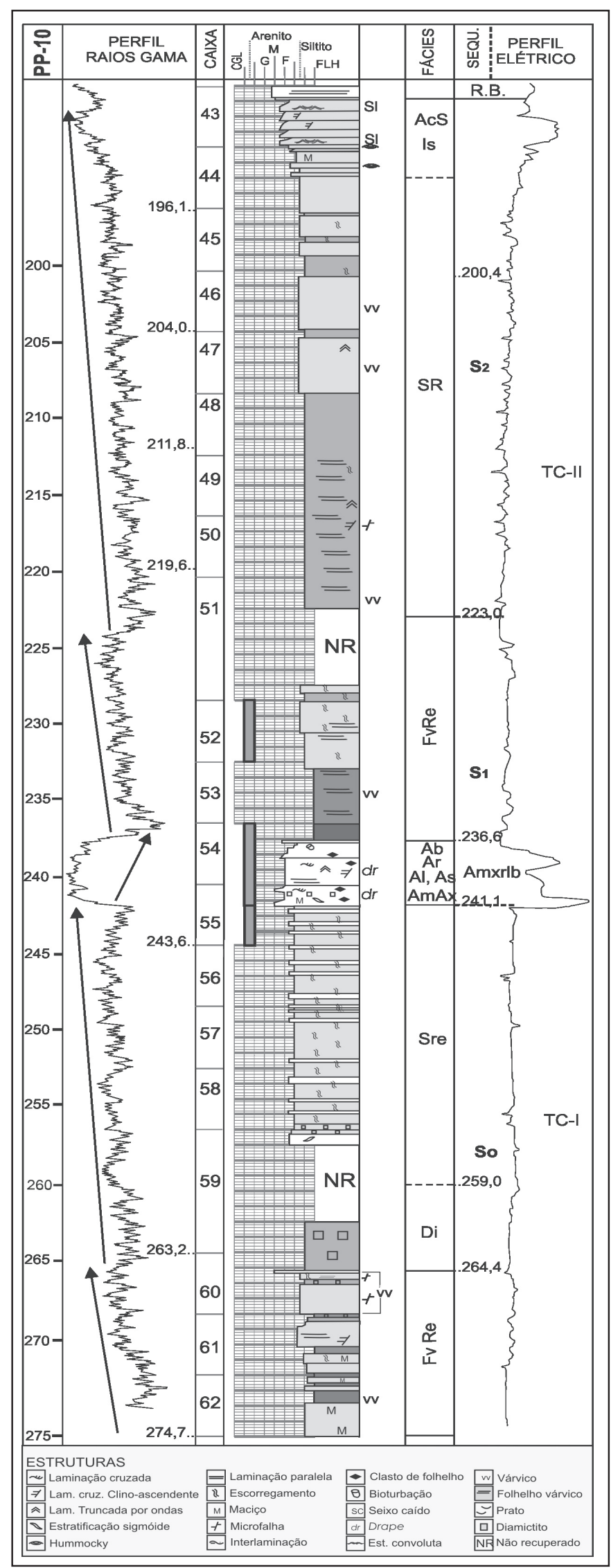

Figura 5. Perfil sedimentológico do poço PP-10. Notar setas indicando ciclos de granocrescência (em forma de funil) nas seqüencias TC-I e TC-II, e um de granodecrescência (forma de sino) no Arenito A4. A seqüência TC-II é dividida em duas de ordem inferior, designadas $S_{1}$ e $S_{2}$, enquanto $S_{0}$ corresponde à TC-I (Castro et al. 2005).
O corpo principal de arenito, entre 55,0 e 2,5m, é constituído de quatro associações faciológicas (em ordem granodecrescente, AmiR, Aml, Alr, AmlrS), distribuídas em três ciclos maiores de granodecrescência ascendente (Figura 2).

$\mathrm{O}$ ciclo inferior tem $30 \mathrm{~m}$ de espessura e é formado pela sucessão de três associações, AmiR, Aml e Alr. A associação AmiR mostra arenito grosso a médio, maciço, e conglomerado intraclástico, sendo os intraclastos formados por ritmito várvico erodido do substrato basal (fácies Rv); localmente também ocorrem clastos arredondados do embasamento (Figuras 2, 4C). $\mathrm{O}$ arenito maciço apresenta duas intercalações de ritmito várvico, cada uma com $8 \mathrm{~cm}$, demonstrando uma estreita relação entre as duas fácies (Figuras 4-C, 4-D). A associação Aml é formada por arenito médio a fino, maciço e raramente com laminação horizontal, e no topo com alguma laminação cruzada clino-ascendente. A associação Alr é representada por estratos, de espessura 0,3 a $2,0 \mathrm{~m}$, com textura gradacional desde fina a muito fina, e estrutura dominada por laminações horizontal e cruzada clino-ascendente; no último metro o arenito passa a muito fino/síltico (Figura 2).

O ciclo intermediário, com $15,5 \mathrm{~m}$, é formado pelas associações Aml e AmlrS. A primeira associação, Aml, apresenta localmente um intervalo rico em pequenos intraclastos argilosos, cuja orientação sugere a presença de estratificação cruzada sigmóide. A associação AmlrS é formada por uma sucessão granodecrescente desde arenito médio até siltito, com estruturas maciça e laminações horizontal e cruzada clino-ascendente (Figuras 2, 4-E).

O ciclo superior tem 7,0m de espessura e apenas uma associação, Aml, onde se destacam intraclastos argilosos na base do ciclo (Figura 2). Os arenitos geralmente são porosos e apresentam-se parcialmente amarelados e com anéis de liesegang, por efeito de laterização de superfície.

As associações faciológicas que formam o espesso corpo arenoso do poço RB-3 são originadas a partir da desaceleração de correntes de turbidez, por decantação seguida de tração (traction plus fallout); as fácies constituintes são identificadas com os intervalos Ta a Te da Seqüência Bouma. A associação subjacente representaria o substrato lacustre-bacial onde se alojou o sistema turbidítico. A presença de intraclastos desse substrato nos arenitos grossos da associação basal AmiR sugere a canalização do leque turbidítico, fato este reforçado pela provável geometria lenticular do espesso corpo arenoso (ver Arenito A3 na figura 7, perfil integrado do Rio Butiá).

Nos 2,5m iniciais do poço foi recuperado $1,0 \mathrm{~m}$ de diamictito cinzento a amarelado, com lâminas arenosas inclinadas (escorregamento?) e delgado nível conglomerático (Fácies Di, figura 2). Tal diamictito tem continuidade na pedreira adjacente, perfazendo uma espessura total de $12,0 \mathrm{~m}$, e faz parte de um grande ciclo de deglaciação iniciado com o arenito turbidítico anterior (ver capítulo arcabouço cronoestratigráfico).

Poço PP-10 O poço PP-10 amostrou 84,0m da Formação Taciba, seguido de 190m da Formação Rio Bonito (sendo os 140m inferiores pertencentes ao Membro Triunfo, pós-glacial). A seção testemunhada da Formação Taciba, predominantemente pelítica (Membro Rio do Sul; França \& Potter, 1988), pode ser dividida em três intervalos: de 275,0 a 241,0m, Pelítico inferior; de 241,0 a 236,5m, Arenoso intermediário; e de 236,5 a 191,5m, Pelítico superior.

O intervalo pelítico inferior apresenta três associações faciológicas: folhelho várvico, siltito e ritmito (FvRe), diamictito (Di) e siltito e ritmito com escorregamento (SRe) (Figura 5).A associação FvRe é constituída de folhelho várvico, com raras lãminas síltico-arenosas, que passa gradualmente a siltito maciço e a ritmito areno-argiloso, composto por uma alternância de 


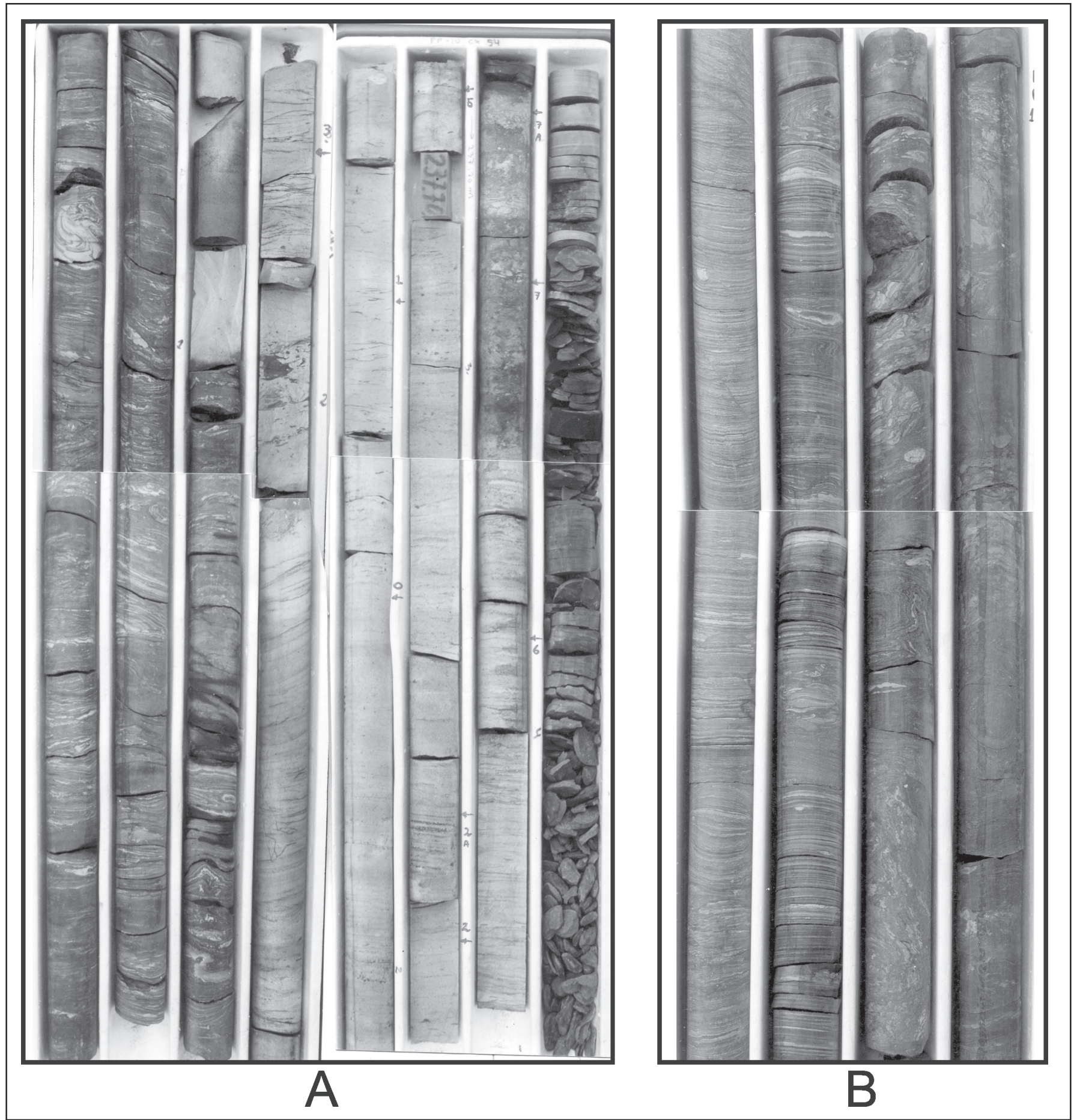

Figura 6. Associações faciológicas do poço PP-10. A. Associações SRe, Amxrlb e FvRe. Siltito e ritmito com escorregamento (SRe), recoberto por Arenito maciço (terceira raia) ou com estratificação e laminação cruzadas, e drapes e intraclastos de folhelho e diamictito; sucedem arenitos com estratificação sigmóide a laminação de baixo ângulo, laminação cruzada com retrabalhamento por ondas e clino-ascendente, e arenito argiloso com forte bioturbação, em contato abrupto com folhelho. B. Associação faciológica FvRe. Ritmito arenito-folhelho com estruturas de escorregamento, e forte deformação nos $2 \mathrm{~m}$ superiores do testemunho; notar clasto caído de $2 \mathrm{~cm}$ (3'. raia). Diâmetro dos testemunhos, 4,5cm; caixas 55/54 e 52, Figura 5. Base no canto inferior esquerdo, topo no lado direito.

folhelho e arenito muito fino, com espessura de cada par entre 2 e 5mm; quando o par é mais espesso, isso se deve à fração arenosa, que pode apresentar laminação cruzada clino-ascendente. A regularidade dos pares sugere tratar-se de varvitos; falhas associadas a escorregamentos ocorrem localmente. A fácies Di tem 5,0m de espessura, sendo representada por diamictito maciço, de textura síltica, com raros clastos caídos (1 a 2cm de diâmetro). A associação SRe contém siltitos e ritmitos areno-argi- losos com feições de escorregamento, pseudonódulos arenosos e raros clastos caídos (Figura 6-A).

Ao se calibrar a descrição dos testemunhos com os perfis raio-gama e elétrico, nota-se no intervalo inferior duas sucessões granocrescentes, representadas pela associação FvRe e pelas associações Di e SRe (Figura 5). O conjunto das duas sucessões revela um ciclo maior de arrasamento ascendente (shallowing upwards): a presença de varvitos e seixos caídos na primeira 


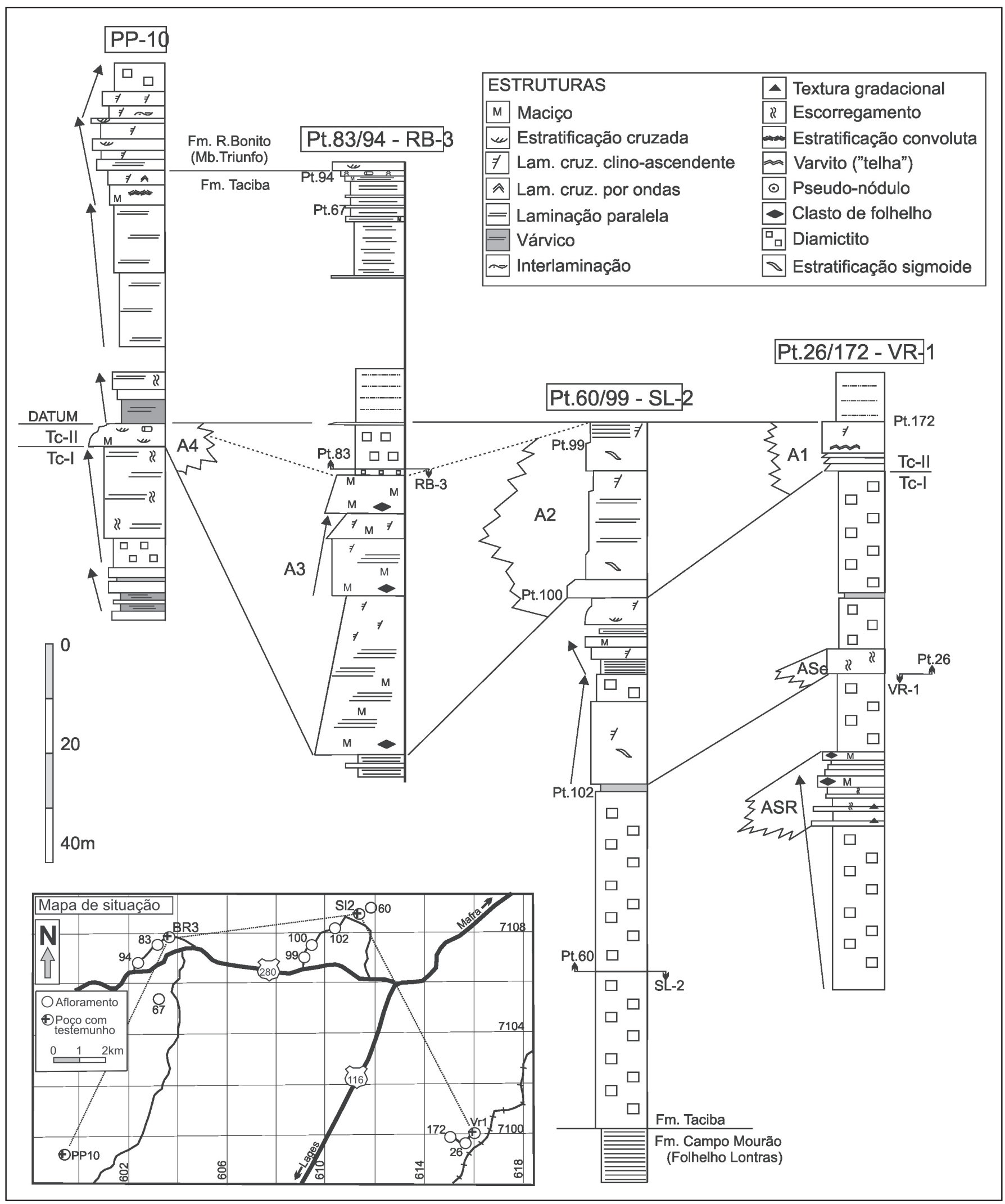

Figura 7. Correlação entre os perfis de poços, complementados com perfis de afloramentos vizinhos, e datum na superficie de inundação máxima da seqüência TC-II; os arenitos Al a A4 formam a porção basal desta seqüência.

associação indica um ambiente gláciolacustre dominado por processos de suspensão, enquanto as feições de escorregamento e liquefação da segunda associação sugerem um contexto mais instável, provavelmente de talude.

$\mathrm{O}$ intervalo Arenoso intermediário, com a associação
Amxrlb, representa um evento de alta energia interposto entre os intervalos peliticos (Arenito A4, Figura 5). Na base, o arenito apresenta-se grosso a médio, maciço, em contato abrupto com o ritmito subjacente; em seguida o arenito torna-se médio a fino, com estratificação e laminação cruzadas, freqüentes drapes ar- 
gilosos e intraclastos de folhelho e de diamictito (Figura 6-A). Mais acima o arenito mostra laminação paralela pouco inclinada seguida de laminação cruzada com intraclastos argilosos, e frequente retrabalhamento por ondas; no último metro, o arenito apresenta base erosiva, afinamento textural de médio a muito fino, laminação cruzada clino-ascendente, tornando-se mais argiloso e fortemente bioturbado para o topo, onde tem raros seixos caídos, (Figura 6-A). O domínio de estruturas tracionais e de suspensão, o retrabalhamento por ondas e marés (drapes e laminações cruzadas de sentidos opostos), e a tendência de afinamento ascendente realçada pela bioturbação no topo, sugere para o intervalo arenoso um ambiente transicional do tipo flúvio-estuarino, em um contexto transgressivo ligado a uma fase de deglaciação, que se completa com 1,0m de folhelho radiativo capeador = nível de inundação máxima (Figuras 5, 6-A).

Este último folhelho já representa a base do intervalo Pelítico superior, que consiste de três associações faciológicas formando duas sucessões/ciclos de granocrescência ascendente: a primeira com a associação RvFe, e a segunda com a associação SR (Figura 5). O primeiro ciclo é formado pela sucessão de folhelho, folhelho várvico e ritmito areno-argiloso, este com feições de escorregamento e raros clastos caídos (associação FvRe, figura 6-B). O ciclo seguinte compõe-se de siltito seguido de ritmito, às vezes com aspecto várvico (associação $\mathbf{S R}$ ), apresentando localmente feições de escorregamento; para o topo ocorre a associação IsAcS com interlaminação arenito-folhelho por ondas de tempestate (Is, "microtempestito"), e arenito com estratificação convoluta gradando a siltito maciço eventualmente com pseudonódulos arenosos (AcS, turbiditos Tcd). As fácies do ciclo superior são dominadas por processos de suspensão, enquanto os ciclos representam arrasamento ascendente, de modo semelhante ao descrito para o intervalo inferior; portanto, pode-se inferir uma origem gláciolacustre ou marinha restrita, em um trato de sistemas de nível de base alto.

Sobrepondo-se à Formação Taciba, em contato abrupto, ocorrem os arenitos deltaicos-dominados por rio, da Formação Rio Bonito/Membro Triunfo (Castro et al. 2005).

ARCABOUÇO CRONOESTRATIGRÁFICO A seção estratigráfica da Figura 7 baseia-se em perfis de três poços "rasos" VR-1, SL-2 e RB-3, complementados com os afloramentos adjacentes a cada poço (pontos $26,60,83$ ), e no perfil do poço "profundo" PP-10. Destaca-se inicialmente a identificação de duas seqüências deposicionais, TC-I e TC-II, e o datum da seção posicionado na superfície de inundação máxima da seqüência TC-II.

A parte inferior da seqüência TC-I revela a seção de $65 \mathrm{~m}$ de diamictito do perfil S. Lourenço, em contato abrupto com o Folhelho Lontras. Tais diamictitos também se fazem presente no perfil Vila Ruthes, agora acompanhados de cunha arenosa-síltica-rítmica (associação ASR) que expressa a chegada de fluxos pastosos (slurries) à bacia. Este processo repete-se mais tarde na mesma área, com a chegada de nova cunha clástica ASR, atualmente aflorante na pedreira adjacente: estes clásticos incluem um bloco preservado de turbidito indicando um contexto relativamente profundo para a deposição da seqüência TC-I, sob influência glacial.

Tal contexto muda na deposição da parte superior da unidade. Nota-se inclusive uma significativa mudança de fácies entre os perfis Vila Ruthes e PP-10/Rio Butiá. No primeiro perfil desenvolve-se um espesso diamictito (quase $30 \mathrm{~m}$ ) e forte contribuição glacial (numerosos clastos caídos com tamanho decimétrico), indicando condições mais rasas e proximais em relação ao contexto anterior, mais profundo. Enquanto isso, os ciclos de granocrescência das associações FvRe e DilSRe (poço PP-10) indicam condições de plataforma mais distal, com forte presença de processos de ressedimentação (escorregamentos); um contexto similar parece ocorrer no perfil Rio Butiá, com a sugestiva granocrescência das fácies Siltito e Ritmito várvicos ( com raros e pequenos clastos caídos) indicando condições plataformais distais (Figura 7).

Interpreta-se a superfície erosiva basal de corpos arenosos variados como um limite de seqüências; tal contato, e a seqüência a ele sobreposta, podem ser seguidos até o sul paranaense (Castro 1999, sua seqüência 4) ou para oeste, no sentido do atual interior da Bacia do Paraná.

A seqüência TC-II começa com um corpo arenoso que apresenta variações significativas de espessura e fácies, relacionado a um nível de mar baixo. No perfil PP-10 dominam arenitos flúvioestuarinos (A4), no perfil Vila Ruthes depósitos de deglaciação (varvitos tipo "telha" e arenitos flúvio-deltaicos A1), e no perfil Rio Butiá o espesso turbidito canalizado "A3", recoberto por diamictito glacial (Figura 7). No perfil de superfície que acompanha o poço SL-2, o arenito A2 revela uma espessa seção flúvio-deltaica, em tudo diferente dos demais arenitos (Figura 7).

O folhelho marinho do perfil Rio Butiá provavelmente representa uma superfície de inundação máxima, enquanto os ciclos granocrescentes amostrados no PP-10 constituem o trato de mar alto de TC-II; este culmina com tempestitos delgados, observados no PP-10 e em pedreira próxima a Bela Vista do Sul, entre os perfis RB-3 e PP-10 (Figura 7; Weinschütz 2001).

Arenitos flúvio-deltaicos da base do Membro Triunfo já pertencem a uma nova seqüência, sobreposta à TC-II (Castro et al., 2005).

CONCLUSÕES A Formação Taciba, unidade superior do Grupo Itararé, constitui uma grande seqüência ou ciclo de afinamento textural ascendente, representado por arenito, diamictito, ritmito e siltito/folhelho, dos membros Rio Segredo, Chapéu do Sol e Rio do Sul (França \& Potter 1988). Aquela unidade corresponde à Formação Rio do Sul (excluindo-se desta o Folhelho Lontras) de Schneider et al. (1974), ou à seqüência Rio do Sul-médio\Rio do Sul-superior proposta por Weinschütz (2001) para a região de Mafra. Poços testemunhados, integrados com os respectivos perfis aflorantes vizinhos, possibilitam construir e correlacionar quatro seções compostas, caracterizando duas seqüências para a Formação Taciba (TC-I e TC-II), que correspondem às duas divisões da "seqüência Rio do Sul"(Weinschütz, 2001).

$\mathrm{Na}$ área de Mafra não ocorre o arenito basal da Formação Taciba (Membro Rio Segredo), que caracteriza o trato de mar baixoltransgressivo da seqüência TC-I; o mesmo é encontrado a oeste, no sentido da atual porção central da Bacia do Paraná, ou para o centro-sul catarinense. Assim, o diamictito Chapéu do Sol sobrepõe-se direta e abruptamente ao Folhelho Lontras; uma significativa coluna de diamictito, contendo níveis de arenito ressedimentado, ocorre no perfil de Vila Ruthes e pode representar o trato de sistema de mar alto de TC-I. Este também inclui, em sua porção superior, as duas sucessões granocrescentes de folhelhos várvicos e delgados ritmitos amostrados no poço PP-10 (Membro Rio do Sul).

A seqüência TC-II inicia com a deposição de sistemas arenosos, com grande variedade de fácies e espessuras. Aí se destaca uma espessa seção de turbidito canalizado no perfil Rio Butiá (Arenito A3), recoberta por diamictito, arenito fossilífero (Rocha-Campos, 1966). e folhelho marinho, numa sucessão transgressiva relacionada a uma deglaciação. No PP-10 o ciclo de fácies do Arenito A4 é de origem flúvio-estuarina, sendo recobertos abruptamente por folhelho marinho. Tal conjunto caracteriza os tratos de mar baixo e transgressivo, equivalente a um ciclo de deglaciação, como os demais arenitos (A1 e A2); sucedem no PP-10 sucessões granocrescentes e de arrasamento ascendente de siltito e ritmito, seguidas de arenitos convolucionados $\backslash$ siltitos liquefeitos e tempestitos delgados para o topo de TC-II, que vêm 
a representar o trato de sistemas de mar alto.

Dentro dessa evolução, sucedem-se os arenitos flúvio-deltaicos pós-glaciais da Formação Rio Bonito/Membro Triunfo, formando nova seqüência deposicional.

Agradecimentos Os autores agradecem à Fundação Vitor De- quech (GEOSOL) pelas sondagens proporcionadas à presente Tese de Doutoramento (LCW), que acrescentaram novos conhecimentos estratigráficos sobre o Grupo Itararé. Os agradecimentos se estendem ao DNPM/CPRM, pelas facilidades oferecidas quanto ao acesso a testemunhos e perfis do poço PP-10. O primeiro autor também agradece ao CNPq pela Bolsa de Doutorado.

\section{Referências}

Castro J.C. 1999. Estratigrafia de Seqüências das formações Campo Mourão (parte superior) e Taciba, Grupo Itararé, leste da Bacia do Paraná. Brasileira de Geociências Revista, 29:255-260.

Castro J.C., Weinschütz L.C., Castro M.R. 2005. Estratigrafia de Seqüências das formações Taciba e Rio Bonito (Membro Triunfo) na região de Mafra/SC, leste da Bacia do Paraná. Boletim de Geociências da Petrobrás, 13:27-42.

França A.B. \& Potter P.E. 1988. Estratigrafia, ambiente deposicional e análise de reservatório do Grupo Itararé (Permocarbonífero), Bacia do Paraná (Parte 1). Boletim de Geociências da Petrobrás, 2:147191.

Rocha-Campos A.C. 1966. Novas ocorrências de fósseis marinhos no Grupo Tubarão em S. Paulo e Santa Catarina. Boletim da Sociedade Brasileira de Geologia, 15:5-13.

Schneider R.L., Mühlmann H., Tommasi E., Medeiros R.A., Daemon
R.F., Nogueira A.A. 1974. Revisão estratigráfica da Bacia do Paraná. In: SBG, Congresso Brasileiro de Geologia, 28, Porto Alegre, Anais, vol p. 41-65.

Weinschütz L.C. 2001. Análise faciológica e estratigráfica do Grupo Itararé (Permocarbonifero) na região de Rio Negro-Mafra, borda leste da Bacia do Paraná. Dissertação de Mestrado, Instituto de Geociências e Ciências Exatas, Universidade Estadual Paulista, $59 \mathrm{p}$.

Weinschütz L.C. \& Castro J.C. 2005. A evolução das formações Mafrasuperior e Rio do Sul-inferior (Grupo Itararé, Permocarbonífero), em sondagens testemunhadas da região de Mafra (SC), margem leste da Bacia do Paraná. Geociências, 24(2):131-141.

Manuscrito A-1570

Revisão aceita em 3 de agosto de 2006 